\title{
Psychotropic drug prescription in adolescents: a retrospective study in a Swiss psychiatric university hospital
}

Nicolas Ansermot*, PhD (1), Véronique Jordanov* $(1,2)$, Michal Smogur, MD (1), Laurent Holzer, MD (3), Chin B. Eap, PhD $(1,2)$

1) Unit of Pharmacogenetics and Clinical Psychopharmacology, Center for Psychiatric Neuroscience, Department of Psychiatry, Lausanne University Hospital, Hospital of Cery, Prilly-Lausanne, Switzerland.

2) School of Pharmaceutical Sciences, University of Geneva, University of Lausanne, Geneva, Switzerland.

3) University Service for Child and Adolescent Psychiatry, Department of Psychiatry, Lausanne University Hospital, Lausanne, Switzerland.

${ }^{*}$ The contributions of these authors have to be considered as equivalent

Running title: Psychotropic drug prescription in adolescents

Corresponding authors: $\operatorname{Dr}$ Nicolas Ansermot and Prof. Chin B. Eap, Unit of Pharmacogenetics and Clinical Psychopharmacology, Center for Psychiatric Neurosciences, Department of Psychiatry, Lausanne University Hospital, Hospital of Cery, 1008 PrillyLausanne, Switzerland. Tel: +41 2131422 75; Fax: +41 2131424 44; E-mail: nicolas.ansermot@chuv.ch, chin.eap@chuv.ch

Statistical consultant: Dr Mehdi Gholam-Rezaee, Centre of Psychiatric Epidemiology and Psychopathology, Department of Psychiatry, Lausanne University Hospital, Switzerland.

Part of this work was presented at the $2^{\text {nd }}$ Swiss Pharmacist Congress (November 3-4, 2014; Interlaken, Switzerland) and the Annual Meeting of the Swiss Association of Public Health Administration and Hospital Pharmacists (November 26-27, 2015; Zurich, Switzerland).

Word count: abstract: 265, manuscript: 5723 


\section{Abstract}

Objectives: This retrospective study aims to evaluate off-label prescriptions and administrations of psychotropic medications in adolescents in a university psychiatric hospital in Switzerland.

Methods: Data were collected during the entire stays from the electronic database for 76 inpatients in 2008 and 76 inpatients in 2014. Data collected included gender, age, psychiatric diagnosis, duration of hospitalization, psychotropic drug prescriptions and administrations.

Results: A total of 224 psychotropic drugs (mean 2.9 drugs/patient) were prescribed in 2008 and 268 (mean 3.5 drugs/patient) in 2014. Due to the prescriptions of some drugs as required, only $76 \%$ of the prescriptions were actually administered in 2008 (mean 2.3 drugs/patient) and 55\% in 2014 (mean 1.9 drugs/patient). Antipsychotics were the most frequently prescribed drugs in 2008 (74\% of patients) and 2014 (86\% of patients). Anxiolytics were also highly prescribed in 2008 (54\% of patients) and 2014 (66\% of patients), as well as antidepressants in 2008 (30\% of patients), but less in 2014 (13\% of patients). Overall, 69\% of prescriptions were found to be off-label in 2008 and $68 \%$ in 2014 , according to age, diagnosis, dose or formulation as approved by Swissmedic. The medication classes with the highest rate of offlabel prescriptions were antidepressants (100\% for both years), antipsychotics (94\% in 2008 , $92 \%$ in 2014) and hypnotics (67\% in 2008, 100\% in 2014). For both study periods, at least one off-label psychotropic drug prescription and administration was recorded in $96 \%$ and $79 \%$ of the patients, respectively.

Conclusion: The high rate of off-label psychotropic drug use strengthens the need for clinical trials to better evaluate the efficacy and safety of these treatments in adolescents.

Keywords: Psychotropic drugs; Off-label use; Adolescents; Hospital; Switzerland 


\section{Introduction}

The prescription of psychotropic drugs among children and adolescents in outpatient settings has increased over the past decades, according to studies performed in the United Kingdom (Hsia and Maclennan 2009), United States (Olfson et al. 2012), Canada (Meng et al. 2014) and Taiwan (Chien et al. 2013). This growing practice is mainly due to the prescription of stimulants, atypical antipsychotics and selective serotonin reuptake inhibitors. In addition, high cross-national differences in the prevalence of psychotropic drugs prescription have been observed. For example, a comparative study performed in 2000 showed a prevalence of $6.7 \%$ in the United States, $2.9 \%$ in the Netherlands and 2.0\% in Germany (Zito et al. 2008).

This high prescription rate raises concerns since a considerable number of these drugs are prescribed off-label. A nationwide survey conducted in Australia among general pediatricians and child and adolescent psychiatrists in 2000 found that $40 \%$ of psychotropic drugs were prescribed off-label (Efron et al. 2003). A study performed among all child psychiatrists in the Netherlands in 2001 showed that for different psychiatric disorders, off-label prescribing varies from 19 to $71 \%$ (Hugtenburg et al. 2005). In Germany, a retrospective cohort study revealed that $49 \%$ of antidepressants were prescribed off-label in 2004-2006 (Dorks et al. 2013).

The notion of off-label refers to the use of a marketed drug in a situation that does not correspond to the terms explicitly recognized by the local authorities, such as Swissmedic in Switzerland or the Food and Drug Administration in the United States. In other terms, the therapeutic indication, the age, the dosage, the pharmaceutical form and/or the route of administration do not correspond to the official authorized use (Neubert et al. 2008). In the United States, according to the Committee on Drugs from the American Academy of Pediatrics, three-fourths of the prescribed medications lack pediatric use information (American Academy of Pediatrics 2002). Only few psychotropic drugs are authorized among this young population for treating mental illnesses such as schizophrenia or depression. In addition, despite that some atypical antipsychotics are approved to treat a range of conditions such as bipolar disorder and childhood schizophrenia, the majority of the pediatric population receiving these drugs are getting them for non-approved psychiatric conditions (Pathak et al. 2010).

To improve the clinical study of drugs in pediatric patients, the FDA Modernization Act (1997), followed by the Best Pharmaceuticals for Children Act (2002), incite drug companies to conduct 
FDA-requested pediatric studies by granting an additional 6 months of marketing exclusivity. The Pediatic Research Equity Act (2003) is a complementary program that authorizes the FDA to require the study of a new drug in pediatric populations (Bourgeois and Hwang 2017). In the European Union, the pharmaceutical companies have to submit a Paediatric Investigation Plan since 2007 , which aimed at ensuring that the necessary data are obtained through studies in children, with the reward of patent extension (European Medicines Agency 2017).

The active compounds approved for children and adolescent use can vary from one country to another according to its regulation policy. Only a few antipsychotics and antidepressants have pediatric indications in Switzerland (Table 1). On the contrary, the most common benzodiazepines are approved in these patients (Swiss Drug Compendium).

The problem is more pronounced for hospitalized patients who received a higher number of psychotropic medications than in the community. Several studies conducted since 1976 have evaluated the prescription of these drugs in children and/or adolescents in psychiatric wards in the USA (Zito et al. 1994; Kaplan and Busner 1997; Safer 1997; Pappadopulos et al. 2002; Kelly et al. 2004; Lekhwani et al. 2004; Najjar et al. 2004; Pathak et al. 2004; Pogge et al. 2007; Meagher et al. 2013; Saldana et al. 2014), Canada (Ahsanuddin et al. 1983; Procyshyn et al. 2014), Finland (Sourander et al. 2002; Haapasalo-Pesu et al. 2004), France (Winterfeld et al. 2008; Consoli et al. 2009), United Kingdom (Akram 2015), Serbia (Pejovic-Milovancevic et al. 2011), Israel (Gilat et al. 2011), Australia (Dean et al. 2006) and China (Song and Guo 2013). The proportion of patients treated with psychotropic medication was high, ranging from $30 \%$ to $100 \%$. Despite the relative important number of studies, the majority have some limitations such as the evaluation of a single prevalence period (Ahsanuddin et al. 1983; Zito et al. 1994; Kaplan and Busner 1997; Pappadopulos et al. 2002; Sourander et al. 2002; Kelly et al. 2004; Lekhwani et al. 2004; Pathak et al. 2004; Dean et al. 2006; Pogge et al. 2007; Winterfeld et al. 2008; Consoli et al. 2009; Pejovic-Milovancevic et al. 2011; Procyshyn et al. 2014; Saldana et al. 2014; Akram 2015), the analysis of prescriptions at a single point during hospitalization (Sourander et al. 2002; Haapasalo-Pesu et al. 2004) or at admission and/or discharge only (Safer 1997; Lekhwani et al. 2004; Gilat et al. 2011; Meagher et al. 2013; Procyshyn et al. 2014; Saldana et al. 2014; Akram 2015), the study of antipsychotics only (Pappadopulos et al. 2002; Kelly et al. 2004; Pogge et al. 2007; Procyshyn et al. 2014; Saldana et al. 2014), or the inclusion of children only (Lekhwani et al. 2004; Pathak et al. 2004; Akram 
2015). The rate of off-label prescriptions was evaluated in only three of these studies, at a single prevalence period (Winterfeld et al. 2008; Procyshyn et al. 2014; Akram 2015), at admission and discharge for antipsychotics (Procyshyn et al. 2014), and at discharge for children (Akram 2015).

To our knowledge, the present study is the first that focused on off-label prescription and administration of psychotropic drugs during the entire hospital stay of adolescents in a psychiatric ward during two separate periods (2008 and 2014).

\section{Methods}

\section{Study design and patients}

A retrospective study including data collected in 2008 and 2014 was conducted among adolescents (12-18 years old) hospitalized at the Unit of Psychiatric Hospitalization for Adolescents (University Service for Child and Adolescent Psychiatry, Department of Psychiatry, Lausanne University Hospital, Switzerland). The study was approved by the local Ethics Committee.

Concerning the data collected in 2008, all patients who were admitted between May $1^{\text {st }}$ and December $31^{\text {st }}, 2008$ were included and followed until the end of their hospitalization. The date of discharge for the hospitalization of the last patient was April $9^{\text {th }}, 2009$. Patients admitted before May $1^{\text {st }}, 2008$ but still hospitalized during the study period were not included. In total, 76 stays were collected over the year 2008.

For data collected in 2014, the first 76 stays were included in order to have the same number as in 2008 , to be able to compare results from both periods. The period of admission lasted from January $13^{\text {th }}$ to July $21^{\text {st }}, 2014$. The date of discharge for the hospitalization of the last patient was August $25^{\text {th }}, 2014$. Patients admitted before January 13, 2014 but still hospitalized during the study period were not included.

All data presented in this study are based on the number of stays, that is, if a patient was hospitalized twice or more during the study period, each stay was considered independently as a new patient.

\section{Data extraction and analyses}


For both periods, data was extracted from the electronic prescription and administration databases. The demographic data collected included gender, age at admission, psychiatric diagnosis at discharge according to the International Statistical Classification of Diseases and Related Health Problems (ICD-10), as well as the number and duration of the hospitalizations for each patient within the study period. All prescribed and administrated psychotropic drugs were collected throughout the entire hospital stay of the patients, including the name of the active compound, the pharmaceutical form, the daily doses and the duration of the prescription and administration. As some drugs were prescribed as required (pro re nata or prn), a distinction was made between prescriptions and administrations. This was possible because all administrations actually performed by the nurses were recorded in the electronic database. The number of different prescribers was also recorded.

For every documented psychotropic drug, the pharmaceutical form was taken into consideration, therefore separating oral from injectable formulations, as well as oral immediate release (IR) from oral extended release (XR) formulations. A total of 5 active compounds were separated in this manner: haloperidol (oral versus injectable), levomepromazine (oral versus injectable), quetiapine (IR versus XR), lorazepam (oral versus injectable) and biperiden (oral versus injectable and IR versus $\mathrm{XR}$ ).

The Anatomical Therapeutic Chemical Classification (ATC) was used in order to characterize each drug class. All drugs that figured in the N05 (psycholeptic drugs) and N06 (psychoanaleptic drugs) classes were included in the extractions, including the phytomedicine.

Drugs from other classes that are usually used in psychiatry were also included, such as lamotrigine (N03AX09), valproate (N03AG01), biperiden (N04AA02) and nicotine (N07BA01). For each patient and each psychotropic drug, the mean prescribed and administered daily dose was calculated.

The number of different drugs that were either prescribed or administered simultaneously in the same patient was also studied. Unlike the rest of the analyses where the pharmaceutical forms were separated, the analyses were made according to the active compound. The pharmaceutical forms were therefore regrouped. The results were expressed in terms of percentage of hospitalization days.

\section{Off-label use}


All prescriptions and administrations were analyzed and categorized for off-label use according to the approved indications in Switzerland at the moment of the study (2008 and 2014, respectively) and the diagnoses of the patients. The reference source employed was the Swiss Drug Compendium, approved by Swissmedic, the Swiss Agency for Therapeutic Products (Swiss Drug Compendium). Reasons for off-label prescriptions and administrations were classified into 6 categories: Age (e.g. citalopram for depression), Diagnosis (e.g. haloperidol for anxiety), Age + Diagnosis (e.g. levomepromazine for depression), Pharmaceutical form (e.g. haloperidol (injectable) for pervasive developmental disorders), Diagnosis + Pharmaceutical form (e.g. quetiapine (XR) for depression) and Dose (ex: lorazepam $17 \mathrm{mg} / \mathrm{d}$ for anxiety). In order to have a comprehensive approach for the examined parameters, a decision-tree was made (Fig. 1).

\section{Statistical analyses}

Pearson $\chi^{2}$ test of independence was used to assess the differences of proportions between 2008 and 2014; in case the validity of Pearson $\chi^{2}$ test was not reliable, the Fisher's Exact test was used instead. Student $t$-test for independent samples was used to compare continuous values between the two study periods; if there were any doubts on the validity of $t$-tests, the Mann-Whitney test was used instead. The number of different psychotropic drugs that were prescribed simultaneously in the same patient was assessed with a Poisson regression analysis, which is a Generalized Linear Model with logarithmic link function, which is the natural link function for count data. A polypharmacy, defined as the simultaneous prescription of 2 psychotropic drugs or more in the same patient, was assessed with a logistic regression. A pvalue $<0.05$ was considered statistically significant. No adjustment for multiple comparisons was performed as the prescription of each drug was considered as a different outcome which should be studied separately. Statistical analyses were performed using Stata software, version 14.0 (StataCorp, College Station, Texas, USA) and R language and environment for statistical computing 3.3.1 (R Core Team (2016). R: A language and environment for statistical computing. R Foundation for Statistical Computing, Vienna, Austria. URL https://www.rproject.org/). 


\section{Results}

\section{Study population}

A total of 76 stays were analyzed in 2008, corresponding to 64 different patients (55 with 1 stay, 6 with 2 stays and 3 with 3 stays). In 2014, a total of 76 stays were also analyzed, corresponding to 64 different patients (57 with 1 stay, 3 with 2 stays, 3 with 3 stays and 1 with 4 stays). Based on the total number of stays, the proportion of females was higher in 2008 (68\%) compared to 2014 (49\%), $p=0.014$. The mean age of patients was slightly higher in 2008 (mean (SD): 16.2 (1.2), range: 12.6-17.9 years) compared to 2014 (mean (SD): 15.5 (1.2), range: $12.4-17.6$ years), $p=0.001$, but this difference was not considered clinically significant. The duration of hospitalizations was not significantly different between 2008 (median (IQR): 17.5 (11-28.5), range: 3-115 days) and 2014 (median (IQR): 17 (13-24), range: 2-142 days), $p=0.90$, corresponding to the analysis of a total of 2094 days of hospitalization in 2008 and 1700 in 2014. There were 7 different prescribers in 2008 and 6 in 2014, with 2 common prescribers between the two periods.

The ICD-10 psychiatric diagnoses were not significantly different between 2008 and 2014 (Table 2). The main diagnoses were F30-39: Mood [affective] disorders (32.9\% of patients in 2008 and $38.2 \%$ in 2014), F40-48: Neurotic, stress related and somatoform disorders (25.0\% in 2008 and $36.8 \%$ in 2014), Z55-65 and Z80-99: Persons with potential health hazards (19.7\% in 2008 and $26.3 \%$ in 2014) and F90-98: Behavioral and emotional disorders with onset usually occurring in childhood and adolescence $(21.1 \%$ in 2008 and $22.4 \%$ in 2014). The mean number of psychiatric diagnoses reported per patient was slightly lower in 2008 compared to 2014 ( 1.8 versus $2.2, p=0.02$ ). The proportion of patients with $1,2,3,4$ and 5 diagnoses was $44.7 \%, 39.5 \%, 13.2 \%, 1.3 \%$ and $1.3 \%$ in 2008 , respectively, and $31.6 \%, 38.2 \%, 14.5 \%, 13.2 \%$ and $2.6 \%$ in 2014 , respectively.

\section{Psychotropic drug prescriptions in 2008 and 2014}

The proportion of patients with at least one psychotropic drug prescription was very high for both years: $94.7 \%$ in 2008 and $96.1 \%$ in 2014 , p=1.0 (Fig. 2) and the number of psychotropic drugs prescribed increased significantly from 2008 ( $n=224$, mean 2.9 per patient) to 2014 ( $\mathrm{n}=268$, mean 3.5 per patient), $p=0.02$ for mean values (Table 3 ). 
The main prescribed drugs for both years were antipsychotics: $n=119$ in 2008 (65 typical and 54 atypical antipsychotics, $53.1 \%$ of prescriptions, $73.7 \%$ of patients) and $n=170$ in 2014 (91 typical and 79 atypical antipsychotics, $63.4 \%$ of prescriptions, $85.5 \%$ of patients). The prescription of antipsychotics increased significantly from 2008 (mean 1.6 per patient) to 2014 (mean 2.2 per patient), $p=0.003$. Levomepromazine was the most prescribed antipsychotics for both years. The prescription of the injectable form increased significantly between 2008 $(n=15)$ and $2014(n=35), p=0.001$, and a trend was observed for the prescription of the oral form ( $n=31$ in 2008, $n=44$ in 2014, $p=0.051$ ). Quetiapine was the second most prescribed antipsychotics. The prescription of the IR form was stable between $2008(n=15)$ and 2014 $(n=22), p=0.26$, but the prescription of the $X R$ form increased significantly ( $n=2$ in $2008, n=34$ in 2014, $p<0.001)$. The prescription of risperidone was stable between $2008(n=15)$ and 2014 $(n=13), p=0.84$. A significant decrease in the prescription was observed for olanzapine (16 in 2008, 5 in 2014, $p=0.02$ ) and chlorprothixene (12 in 2008, 1 in 2014, $p=0.002$ ).

The second therapeutic drug class with the highest rate of prescription was anxiolytics for both study periods: $n=48$ in 2008 (21.4\% of prescriptions, 53.9\% of patients) and $n=53$ in 2014 (19.8\% of prescriptions, $65.8 \%$ of patients). The prescription frequency for anxiolytics was stable from 2008 (mean 0.63 per patient) to 2014 (mean 0.7 per patient), $p=0.34$. Oral lorazepam was largely prescribed in both years: $n=39$ in 2008 and $n=48$ in 2014, $p=0.19$.

The prescription of antidepressants decreased significantly from $2008(n=23$, mean 0.3 per patient, $10.3 \%$ of prescriptions, $30.3 \%$ of patients) to 2014 ( $n=11$, mean 0.14 per patient, $4.1 \%$ of prescriptions, $13.2 \%$ of patients), $p=0.01$ for mean values. Citalopram was the most frequently prescribed antidepressant in $2008(n=12)$, but its prescription decrease significantly in $2014(\mathrm{n}=1, p=0.002)$. Inversely, the prescription of sertraline was low in $2008(n=1)$, but increased significantly in $2014(\mathrm{n}=9, p=0.02)$.

The prescription of phytomedicine was stable for both years: $n=11$ in 2008 (mean 0.14 per patient, $4.9 \%$ of prescriptions, $11.8 \%$ of patients) and $n=13$ in 2014 (mean 0.17 per patient, $4.9 \%$ of prescriptions, $14.5 \%$ of patients), $p=0.62$ for mean values.

The prescription of hypnotics had a tendency to decrease from 2008 ( $n=9$, mean 0.12 per patient, $4.0 \%$ of prescriptions, $7.9 \%$ of patients) to 2014 ( $n=1$, mean 0.01 per patient, $0.4 \%$ of 
prescriptions, $1.3 \%$ of patients), $p=0.052$ for mean values. The prescription of zolpidem decreased significantly from $2008(n=6)$ to $2014(n=0), p=0.03$.

Up to 5 (mean 1.9) and 6 (mean 2.8) different psychotropic drugs were prescribed simultaneously in the same patient in 2008 and 2014, respectively (Fig. 3a). According to results of the Poisson regression model, there is a significant increase in the frequency of prescribed psychotropics in 2014 compared to $2008(\beta=0.40, p=0.01)$. A polypharmacy, defined as the simultaneous prescription of 2 psychotropic drugs or more in the same patient, shows a significant increase from 2008 to 2014 with $59.3 \%$ and $92.1 \%$ of hospitalization days, respectively (using a logistic regression model: $\beta=3.1, p<0.0001$ ).

\section{Psychotropic drug administrations in 2008 and 2014}

The proportion of patients with a least one psychotropic drug administration was $78.9 \%$ in 2008 and $77.6 \%$ in 2014, $p=1.0$ (Fig. 2). A total of 171 psychotropic drugs were administered in 2008 (mean 2.3 per patient, $76.3 \%$ of drug prescribed) and 147 in 2014 (mean 1.9 per patient, 54.9\% of drug prescribed), $p=0.23$ for mean values, see supplementary file (Table S1). For both years, the number of drugs administered was significantly lower than the number of drug prescribed: mean 2.3 and 2.9 per patient in 2008, respectively, $(p=0.02)$ and mean 1.9 and 3.5 per patient in 2014, respectively, $(p<0.0001)$.

The main administered drugs for both years were antipsychotics: $n=96$ in 2008 (43 typical and 53 atypical antipsychotics, corresponding to $56.1 \%$ of administrations and $67.1 \%$ of patients) and $n=98$ in 2014 (27 typical and 71 atypical antipsychotics, $66.7 \%$ of administrations, $71.1 \%$ of patients). The administration of antipsychotics was stable for both years (mean 1.3 per patient in 2008 and 2014, $p=0.71$ ). In 2008, the most administered antipsychotic was levomepromazine. The administration of the oral form was stable between $2008(n=22)$ and $2014(\mathrm{n}=21), p=1.0$, but the administration of the injectable form decreased significantly (10 in 2008, 2 in 2014, $p=0.03$ ). In 2014, on the other hand, the most administered antipsychotic was quetiapine. The administration rate of the IR form was stable between $2008(n=14)$ and 2014 $(n=14), p=1.0$, but the administration rate of the XR form increased significantly ( 2 in 2008, 34 in 2014, $p<0.001)$. The administrations of risperidone were stable between $2008(n=15)$ and $2014(n=13), p=0.84$. The administrations of olanzapine (16 in 2008, 5 in 2014, $p=0.02$ ) and chlorprothixene (8 in 2008, 0 in 2014, $p=0.006$ ) decreased significantly. 
The second therapeutic class of drugs with the highest rate of administration was anxiolytics for both years: $n=28$ in 2008 (16.4\% of administrations, $31.6 \%$ of patients) and $n=24(16.3 \%$ of administrations, $27.6 \%$ of patients). The administration of anxiolytics was stable from 2008 (mean 0.38 per patient) to 2014 (mean 0.32 per patient), $p=0.70$. In both study periods, oral lorazepam was the anxiolytic the most administered: $\mathrm{n}=22$ in 2008 and $\mathrm{n}=20$ in 2014, $p=0.86$.

The administration of antidepressants decreased significantly from 2008 ( $n=22$, mean 0.29 per patient, $12.9 \%$ of administrations, $28.9 \%$ of patients $)$ to $2014(\mathrm{n}=10$, mean 0.13 per patient, $6.8 \%$ of administrations, $11.8 \%$ of patients), $p=0.01$ for mean values. As for the prescriptions, the most frequently administered antidepressant in 2008 was citalopram $(n=12)$, while it was sertraline in $2014(n=8)$.

The administration of phytomedicine tended to decrease from $2008(n=10$, mean 0.13 per patient, $5.8 \%$ of administrations, $11.8 \%$ of patients) to $2014(n=5$, mean 0.07 per patient, $3.4 \%$ of administrations, $3.9 \%$ of patients), $p=0.08$ for mean values.

The administration of hypnotics tended to decrease from 2008 ( $n=9$, mean 0.12 per patient, $5.3 \%$ of administrations, $7.9 \%$ of patients) to $2014(n=1$, mean 0.01 per patient, $0.7 \%$ of administrations, $1.3 \%$ of patients), $p=0.052$ for mean values. The administration of zolpidem decreased significantly from $2008(n=6)$ to $2014(n=0), p=0.03$.

Up to 4 different psychotropic drugs were administered simultaneously in the same patient in 2008 (mean 1.1) and 2014 (mean 1.0), see Fig. 3b. A Poisson regression model failed to detect any significant differences between the two time periods $(\beta=-0.02, p=0.95)$. A polypharmacy was observed in $29.9 \%$ and $33.1 \%$ of the hospitalization days in 2008 and 2014 , respectively, which was not significantly different between the two time periods based on a logistic regression model $(\beta=-0.46, p=0.36)$.

\section{Off-label prescriptions in 2008 and 2014}

A high proportion of off-label prescriptions was observed, with $67.9 \%$ of all psychotropic drugs in 2008 and $67.5 \%$ in $2014, p=0.94$ (Table 3). The therapeutic drug classes with the highest rate of off-label prescriptions were antidepressants (100\% in 2008 and 2014), followed by antipsychotics $(94.1 \%$ in $2008,91.8 \%$ in $2014, p=0.50)$ and hypnotics $(66.7 \%$ in $2008,100 \%$ in $2014, p=1.0)$. The proportion of off-label prescriptions was low for anxiolytics ( $16.7 \%$ in 2008 , $11.3 \%$ in $2014, p=0.57$ ) and no off-label prescriptions were observed for phytotherapy. 
A very high proportion of patients (96.1\% for both years) were prescribed at least 1 off-label psychotropic drug during their hospitalization (Fig. 4). Up to 7 and 6 different off-label prescriptions were recorded in the same patient in 2008 and 2014, respectively.

\section{Off-label administrations in 2008 and 2014}

The rates of off-label administrations were similar to those of the off-label prescriptions, i.e. $71.3 \%$ in 2008 and $71.4 \%$ in 2014, $p=1.0$ (supplementary file Table S1). The highest off-label administrations rate was also observed for antidepressants (100\% in 2008 and 2014), followed by antipsychotics $(92.7 \%$ in $2008,90.8 \%$ in $2014, p=0.80)$ and hypnotics $(66.7 \%$ in $2008,100 \%$ in $2014, p=1.0)$. Off-label administrations were low for anxiolytics $(10.7 \%$ in $2008,0 \%$ in 2014 , $p=0.24)$ and were not observed for phytotherapy.

A high proportion of patients (78.9\% for both years) were administered at least 1 off-label psychotropic drug during their stay (Fig. 4). Up to 6 different off-label administrations were recorded in the same patient in 2008 and 2014.

\section{Reasons for off-label prescriptions and administrations}

The most frequent category of off-label use in 2008 was "Age + Diagnosis" (64 prescriptions, 57 administrations) followed by "Age" (59 prescriptions, 47 administrations), see Fig. 1. In 2014, the most common category of off-label use was "Age" (69 prescriptions, 31 administrations) followed by "Diagnosis" (34 prescriptions, 29 administrations).

\section{Discussion}

This retrospective study, which should be considered as exploratory, showed a high prevalence of psychotropic drug prescriptions (around 95\%) and administrations (around 78\%) in adolescents in a Swiss psychiatric university hospital over the years 2008 and 2014. Globally, the prevalence observed in our study is comparable to those observed in others studies performed in children and/or adolescents hospitalized in psychiatry (Ahsanuddin et al. 1983; Zito et al. 1994; Kaplan and Busner 1997; Safer 1997; Sourander et al. 2002; HaapasaloPesu et al. 2004; Lekhwani et al. 2004; Najjar et al. 2004; Pathak et al. 2004; Dean et al. 2006; Winterfeld et al. 2008; Consoli et al. 2009; Pejovic-Milovancevic et al. 2011; Meagher et al. 2013; Akram 2015). However, large differences have been observed between these studies with a prevalence of psychotropic drug use ranging from 30-100\%. These differences could be 
explained by different factors such as the countries, the year of the studies, the type of hospital, the profile of the patients or the design of the studies.

In our study, the number of drugs prescribed simultaneously in the same patient increased between 2008 (mean 1.9) and 2014 (mean 2.8). However, the number of drugs administered simultaneously was lower and stable between the two study periods (mean 1.1 in 2008 and mean 1.0 in 2014), which indicates that many drugs were prescribed as required (prn medications) and actually not administered. Our results are in line with those observed in different studies conducted in children and adolescents in psychiatry inpatient units of different countries, with an average number of psychotropic medications per patient during the stay or at discharge varying from 0.8 to 3.1 (Pappadopulos et al. 2002; Dean et al. 2006; Winterfeld et al. 2008; Meagher et al. 2013; Song and Guo 2013).

High percentages of off-label prescriptions (68\%) and administrations $(71 \%)$ were observed in the present study, with quite similar results between 2008 and 2014. The rate of off-label prescriptions is very close to that found in the study of Winterfeld et al. performed in children and adolescents hospitalized in psychiatric units of a teaching hospital in France in 2006, with $69 \%$ of off-label prescriptions (Winterfeld et al. 2008). In both periods of our study, at least one off-label psychotropic prescription and administration was recorded in $96 \%$ and $79 \%$ of the patients, respectively. A lower prevalence was observed in the study of Winterfeld et al. where only $34 \%$ of the patients received one or more off-label psychotropic drugs (Winterfeld et al. 2008). Another study conducted in a children's psychiatric unit in United Kingdom from 1997 to 2012 , found that on discharge only $25 \%$ of the patients were prescribed an unlicensed medicine or a licensed drug used in an unlicensed manner (Akram 2015).

\section{Antipsychotic use}

The antipsychotics were the most frequently used drugs in this study. The prescription increased between 2008 and 2014, mostly due to the higher prescription of levomepromazine and quetiapine XR. However, the administrations of antipsychotics were stable between 2008 and 2014. The administration of quetiapine XR increased between the two study periods, but

this was compensated by a decrease in the administration of injectable levomepromazine, olanzapine and chlorprothixene. Due to its sedative properties, injectable levomepromazine was prescribed most of the time as required. Levomepromazine is not approved in Switzerland 
in patients under the age of 18 years but, in other countries such as France, the oral formulation is licensed for the treatment of severe behavioral disorders in pediatric patients (Dictionnaire Vidal 2015). The higher prescription rate of quetiapine XR in 2014 compared to 2008 can be explained by the fact that this new formulation arrived in the marked in Switzerland at the end of 2008. The IR formulation obtained the pediatric approval from Swissmedic in 2010 (Table 1), but its prescription rate didn't increase significantly between 2008 and 2014, indicating the preference of the prescribers for the XR formulation.

By analyzing the prescribing and administration patterns, we found that the majority of typical antipsychotics were prescribed as required and were actually not administered (only $44 \%$ of the prescriptions were administered), whereas this was less the case for atypical antipsychotics (93\% of the prescriptions were administered). According to the American Academy of Child and Adolescent Psychiatry (AACAP) Guidelines, atypical antipsychotics are considered as being the treatment of first choice for schizophrenia (except for olanzapine and clozapine) (McClellan and Stock 2013). The main atypical antipsychotic drugs used in this study were quetiapine, olanzapine and risperidone. These second-generation agents induce lower rates of extrapyramidal adverse effects, but cause greater weight gain and metabolic risk than the typical antipsychotics (De Hert et al. 2011; Cohen et al. 2012). Furthermore, hyperprolactinemia is observed frequently with some atypical antipsychotics, such as risperidone. The prescription rate of olanzapine decreased between 2008 and 2014, which could be due to the consideration of the highest risk of weight gain with this molecule.

In addition to quetiapine, the antipsychotics haloperidol, risperidone and aripiprazole have pediatric indications in Switzerland (Table 1). It is interesting to point out that even though aripiprazole obtained the pediatric approval of Swissmedic for the treatment of schizophrenia in 2009 and mania in 2013, the prescription rate seems to be quite stable between 2008 and 2014. Its approval does therefore not seem to have an impact on the prescription rate.

It is also important to notice the high proportion of antipsychotics that were prescribed off-label (92-94\%), which highlights the need to evaluate the aspects of safety, risks and benefits. In pediatric patients hospitalized in psychiatry units in France, Winterfeld et al. found that $90 \%$ of antipsychotic drugs were prescribed off-label (Winterfeld et al. 2008). In children and adolescents discharged from a tertiary care inpatient psychiatric facility in 2008-2009 in Canada, there were no Health Canada-approved indications for any of the second generation 
antipsychotics prescribed at the time of the study. Based on the FDA indications, the rate of off-label prescribing was $90.5 \%$ at discharge (Procyshyn et al. 2014). For the vast majority of the patients included in our study, adequate doses were prescribed and administered. However, there were some exceptions such as haloperidol with the prescription of up 30 $\mathrm{mg} /$ day and administration of up to $21 \mathrm{mg} /$ day, whereas the recommendation is at $0.5-10$ $\mathrm{mg} /$ day for the treatment of mania in adolescents.

\section{Antidepressant use}

The prescription of antidepressants decreased between 2008 and 2014. A possible explanation could be the instauration of the Black-box warning about the use of antidepressants and their risk of suicidality in the pediatric population by the FDA in 2004. In fact, several papers have noticed a massive drop in the rates of antidepressant prescriptions in children and adolescents following the FDA warning (Kurian et al. 2007; Libby et al. 2007; Mittal et al. 2014). Even though the Black-box warning was introduced a couple of years before our study, the impact of this warning might have been reached several years after.

A reversal in the prescription pattern of antidepressants can also be seen: the use of citalopram decreased from 2008 to 2014, whereas the use of sertraline increased. A potential explanation might have been the warnings issued by the FDA in 2011 for the QTc interval prolongation with citalopram (US Food and Drug Administration 2012). The change in the prescription pattern was considered as adequate, with less risk of cardiotoxicity with sertraline.

In Switzerland, no antidepressant has been approved for the treatment of depression in patients under the age of 18 years. Some of them are indicated in the treatment of obsessive compulsive disorder (OCD) in children and adolescents (Table 1). However, in our study, no patient had this diagnosis, which explains that we found a rate of off-label prescription of $100 \%$ for antidepressants. Fluoxetine ( $\geq 8$ years) and escitalopram ( $\geq 12$ years) are indicated in the US for treating depression in pediatric patients. Fluoxetine has also obtained the approval by the European Medicines Agency (EMA) for treating depression ( $\geq 8$ years) (European Medicines Agency 2006). The fact that fluoxetine was prescribed only once in 2008 and not prescribed at all in 2014 is quite striking, especially since, according to the National Institute for Health and Care Excellence Guidelines (NICE 2005, update 2015) fluoxetine is the firstchoice antidepressant for the treatment of moderate to severe depression among children and 
adolescents (National Institute for Health and Care Excellence 2015). Furthermore, according to a recent network meta-analysis, fluoxetine was the only antidepressant statistically significantly more effective than placebo in children and adolescents with major depressive disorder (Cipriani et al. 2016). Our results are in accordance with the study of Winterfeld et al., which found that $89 \%$ of the antidepressants were prescribed off-label (Winterfeld et al. 2008).

\section{Anxiolytic and hypnotic use}

The anxiolytic drugs come in second place after the antipsychotics in terms of prescription rate, with similar number of prescriptions between the two study periods. These drugs were mainly prescribed as prn medications, with only $58 \%$ and $45 \%$ of the prescriptions actually administered in 2008 and 2014, respectively. The percentages of off-label prescriptions (11$17 \%)$ are one of the lowest comparing to the rest of the psychotropic drugs. The explanation is that the majority of the anxiolytics prescribed are indicated in Switzerland for the treatment of anxiety in children and/or adolescent (Table 1). The main reasons for off-label prescription were a dose higher than recommended or parenteral administration. In the study of Winterfeld et al., $28 \%$ of anxiolytics were prescribed off-label (Winterfeld et al. 2008).

Regarding the use of the hypnotics, a substantial decrease in their prescription rate can be seen from 2008 to 2014. This decrease can be perceived as a good evolution since none of the hypnotics are currently recommended among the pediatric population (Table 1).

\section{Strengths and limitations}

A strength of this study is that this is the first that recorded off-label use of psychotropic medications during the entire psychiatric hospital stay of adolescents at two separated time periods. Another strength is that, in order to have a more realistic and accurate idea of the use of off-label psychotropic medications in pediatric patients, both prescriptions and administrations were recorded. Indeed, some drugs were prescribed as required, which could lead to an overestimation of their use if they were not administered. In addition, some drugs prescribed on a regular basis could have not been administered if the patient refused the treatment, with is quiet common in psychiatry.

There are some limitations to this retrospective study, which should be considered as descriptive and exploratory. First, the differences of prescriptions between the two study periods could have been related to a change of prescribers with different individual habits, 
rather than a real evolution of the practices in general. Indeed, the number of different prescribers was relatively low (7 in 2008 and 6 in 2014), with only 2 common prescribers between the two periods. Secondly, it was not possible to know whether all drugs that were administered were actually validated by nurses in the electronic database and, inversely, if all drugs validated were actually administered; a slight over or under estimation of the real administration rates cannot therefore be totally excluded. Thirdly, although some differences were statistically significant between the two study periods, the results should be considered with caution, as the sample studied was relatively small. Furthermore, it is not possible to know if the prescription pattern observed reflects only local practices or if it could be extrapolated to other psychiatric hospitals in Switzerland or in Europe.

\section{Conclusion}

This retrospective study showed a high prevalence of psychotropic drug use in adolescents in a psychiatric university hospital in Switzerland. An increase in the number of prescriptions was observed between 2008 and 2014, but the number of administrations was stable. Antipsychotics were the most frequently prescribed and administered drugs, followed by anxiolytics. In addition, a high proportion of these drugs were prescribed and administered offlabel according to the indications approved in Switzerland for both study periods. The therapeutic drug classes with the highest rate of off-label prescriptions and administrations were antidepressants, followed by antipsychotics.

\section{Clinical Significance}

A high proportion of off-label psychotropic drug use was observed in this study, despite a lack of proven efficacy for most drugs. These results highlight the need for new clinical trials in order to evaluate the risks and benefits of psychotropic medications in patients under the age of 18 years. At the same time, evaluating clinical practice patterns as well as engaging in the education of the clinicians concerning the known safety and efficacy of psychotropic drugs is an important factor to consider. 


\section{Acknowledgements}

We wish to thank Dr Mehdi Gholam-Rezaee (Centre of Psychiatric Epidemiology and Psychopathology, Department of Psychiatry, Lausanne University Hospital, Switzerland) for his help with statistical analyses.

\section{References}

Ahsanuddin KM, Ivey JA, Schlotzhauer D, Hall K and Prosen H: Psychotropic medication prescription patterns in 100 hospitalized children and adolescents. J Am Acad Child Psychiatry 22:361-364, 1983.

Akram G: Profiling psychotropic discharge medication from a children's psychiatric ward. Int J Clin Pharm 37:753-7, 2015.

American Academy of Pediatrics: Committee on Drugs: Uses of Drugs Not Described in the Package Insert (Off-Label Uses). Pediatrics 110:181-183, 2002.

Bourgeois FT and Hwang TJ: The Pediatric Research Equity Act Moves Into Adolescence. JAMA 317:259-260, 2017.

Chien IC, Hsu YC, Tan HK, Lin CH, Cheng SW, Chou YJ and Chou P: Trends, correlates, and disease patterns of antidepressant use among children and adolescents in Taiwan. $\mathrm{J}$ Child Neurol 28:706-712, 2013.

Cipriani A, Zhou X, Del Giovane C, Hetrick SE, Qin B, Whittington C, Coghill D, Zhang Y, Hazell P, Leucht S, Cuijpers P, Pu J, Cohen D, Ravindran AV, Liu Y, Michael KD, Yang L, Liu $\mathrm{L}$ and Xie P: Comparative efficacy and tolerability of antidepressants for major depressive disorder in children and adolescents: a network meta-analysis. Lancet 388:881-890, 2016.

Cohen D, Bonnot O, Bodeau N, Consoli A and Laurent C: Adverse effects of secondgeneration antipsychotics in children and adolescents: a Bayesian meta-analysis. J Clin Psychopharmacol 32:309-316, 2012. 
Consoli A, Brunelle J, Bodeau N, Perisse D, Deniau E, Guile JM and Cohen D: Medication use in adolescents treated in a French psychiatric setting for acute manic or mixed episode. $\mathrm{J}$ Can Acad Child Adolesc Psychiatry 18:231-238, 2009.

De Hert M, Dobbelaere M, Sheridan EM, Cohen D and Correll CU: Metabolic and endocrine adverse effects of second-generation antipsychotics in children and adolescents: A systematic review of randomized, placebo controlled trials and guidelines for clinical practice. Eur Psychiatry 26:144-158, 2011.

Dean AJ, McDermott BM and Marshall RT: Psychotropic medication utilization in a child and adolescent mental health service. J Child Adolesc Psychopharmacol 16:273-285, 2006.

Dictionnaire Vidal. 91 ed. Paris: Edition du Vidal; 2015.

Dorks M, Langner I, Dittmann U, Timmer A and Garbe E: Antidepressant drug use and offlabel prescribing in children and adolescents in Germany: results from a large populationbased cohort study. Eur Child Adolesc Psychiatry 22:511-518, 2013.

Efron D, Hiscock H, Sewell JR, Cranswick NE, Vance AL, Tyl Y and Luk ES: Prescribing of psychotropic medications for children by Australian pediatricians and child psychiatrists. Pediatrics 111:372-375, 2003.

European Medicines Agency (EMA): Paediatric investigation plans. http://www.ema.europa.eu/ema/index.jsp?curl=pages/regulation/general/general content 00 0608.jsp\&. Last access August 21, 2017.

European Medicines Agency (EMA): Questions and answers on the review of Prozac for use in children and adolescents; 2006. EMEA/198323/2006. http://www.ema.europa.eu/docs/en GB/document library/Referrals document/Prozac 6 12/ WC500013226.pdf. Last access May 4, 2015. 
Gilat Y, Ben-Dor DH, Magen A, Wolovick L, Vekslerchik M, Weizman A and Zalsman G: Trends in prescribing of psychotropic medications for inpatient adolescents in Israel: a 10 years retrospective analysis. Eur Psychiatry 26:265-269, 2011.

Haapasalo-Pesu KM, Erkolahti R, Saarijarvi S and Aalberg V: Prescription of psychotropic drugs in adolescent psychiatry wards in Finland. Nord J Psychiatry 58:213-218, 2004.

Hsia $\mathrm{Y}$ and Maclennan K: Rise in psychotropic drug prescribing in children and adolescents during 1992-2001: a population-based study in the UK. Eur J Epidemiol 24:211-216, 2009.

Hugtenburg JG, Heerdink ER and Tso YH: Psychoactive drug prescribing by Dutch child and adolescent psychiatrists. Acta Paediatr 94:1484-1487, 2005.

Kaplan SL and Busner J: Prescribing practices of inpatient child psychiatrists under three auspices of care. J Child Adolesc Psychopharmacol 7:275-286, 1997.

Kelly DL, Love RC, MacKowick M, McMahon RP and Conley RR: Atypical antipsychotic use in a state hospital inpatient adolescent population. J Child Adolesc Psychopharmacol 14:7585, 2004.

Kurian BT, Ray WA, Arbogast PG, Fuchs DC, Dudley JA and Cooper WO: Effect of regulatory warnings on antidepressant prescribing for children and adolescents. Arch Pediatr Adolesc Med 161:690-696, 2007.

Lekhwani M, Nair C, Nikhinson I and Ambrosini PJ: Psychotropic prescription practices in child psychiatric inpatients 9 years old and younger. J Child Adolesc Psychopharmacol 14:95-103, 2004.

Libby AM, Brent DA, Morrato EH, Orton HD, Allen R and Valuck RJ: Decline in treatment of pediatric depression after FDA advisory on risk of suicidality with SSRIs. Am J Psychiatry 164:884-891, 2007. 
McClellan J and Stock S: Practice Parameter for the Assessment and Treatment of Children and Adolescents with Schizophrenia. Journal of the American Academy of Child \& Adolescent Psychiatry 52:976-990, 2013.

Meagher SM, Rajan A, Wyshak G and Goldstein J: Changing trends in inpatient care for psychiatrically hospitalized youth: 1991-2008. Psychiatr Q 84:159-168, 2013.

Meng X, D'Arcy C and Tempier R: Long-term trend in pediatric antidepressant use, 1983-2007: a population-based study. Can J Psychiatry 59:89-97, 2014.

Mittal M, Harrison DL, Miller MJ and Brahm NC: National antidepressant prescribing in children and adolescents with mental health disorders after an FDA boxed warning. Res Social Adm Pharm 10:781-790, 2014.

Najjar F, Welch C, Grapentine WL, Sachs H, Siniscalchi J and Price LH: Trends in psychotropic drug use in a child psychiatric hospital from 1991-1998. J Child Adolesc Psychopharmacol 14:87-93, 2004.

Nationale Institute for Health and Care Excellence (NICE): Depression in children and young people: Identification and 2015. https://www.nice.org.uk/guidance/cg28/resources/depression-in-children-and-young-peopleidentification-and-management-975332810437. Last access May 25, 2015.

Neubert A, Wong ICK, Bonifazi A, Catapano M, Felisi M, Baiardi P, Giaquinto C, Knibbe CAJ, Sturkenboom MCJM, Ghaleb MA and Ceci A: Defining off-label and unlicensed use of medicines for children: Results of a Delphi survey. Pharmacological Research 58:316-322, 2008.

Olfson M, Blanco C, Liu SM, Wang S and Correll CU: National trends in the office-based treatment of children, adolescents, and adults with antipsychotics. Arch Gen Psychiatry 69:1247-1256, 2012. 
Pappadopulos E, Jensen PS, Schur SB, Maclntyre JC, 2nd, Ketner S, Van Orden K, Sverd J, Sardana S, Woodlock D, Schweitzer R and Rube D: "Real world" atypical antipsychotic prescribing practices in public child and adolescent inpatient settings. Schizophr Bull 28:111$121,2002$.

Pathak P, West D, Martin BC, Helm ME and Henderson C: Evidence-based use of secondgeneration antipsychotics in a state Medicaid pediatric population, 2001-2005. Psychiatr Serv 61:123-129, 2010.

Pathak S, Arszman SP, Danielyan A, Johns ES, Smirnov A and Kowatch RA: Psychotropic utilization and psychiatric presentation of hospitalized very young children. $\mathrm{J}$ Child Adolesc Psychopharmacol 14:433-442, 2004.

Pejovic-Milovancevic M, Miletic V, Popovic-Deusic S, Draganic-Gajic S, Lecic-Tosevski D and Marotic V: Psychotropic medication use in children and adolescents in an inpatient setting. Psychiatriki 22:314-319, 2011.

Pogge DL, Young K, Insalaco B and Harvey PD: Use of atypical antipsychotic medications in adolescent psychiatric inpatients: a comparison with inpatients who did not receive antipsychotic medications during their stay. Int J Clin Pract 61:896-902, 2007.

Procyshyn RM, Su J, Elbe D, Liu AY, Panenka WJ, Davidson J, Honer WG and Barr AM: Prevalence and patterns of antipsychotic use in youth at the time of admission and discharge from an inpatient psychiatric facility. J Clin Psychopharmacol 34:17-22, 2014.

Safer DJ: Changing patterns of psychotropic medications prescribed by child psychiatrists in the 1990s. J Child Adolesc Psychopharmacol 7:267-274, 1997.

Saldana SN, Keeshin BR, Wehry AM, Blom TJ, Sorter MT, DelBello MP and Strawn JR: Antipsychotic polypharmacy in children and adolescents at discharge from psychiatric hospitalization. Pharmacotherapy 34:836-844, 2014. 
Song QY and Guo LT: Trends in the prescribing of psychotropic medications for inpatient children and adolescents, 2000-2010: a study from China. Int Clin Psychopharmacol 28:193199, 2013.

Sourander A, Ellila H, Valimaki M and Aronen ET: Psychopharmacological treatment of child and adolescent psychiatric inpatients in Finland. J Child Adolesc Psychopharmacol 12:147155, 2002.

Swiss Drug Compendium. http://www.compendium.ch. Last access August 21, 2017.

US Food and Drug Administration. FDA drug safety communication: abnormal heart rhythms associated with high doses of Celexa (citalopram hydrobromide) August 24, 2011. http://www.fda.gov/Drugs/DrugSafety/ucm269086.htm. Updated March, 28, 2012. Last access June 29, 2016.

Winterfeld U, Le Heuzey MF, Acquaviva E, Mouren MC, Brion F and Bourdon O: Psychotropic medication use in the child and adolescent psychiatry wards of a French hospital. Pharm World Sci 30:600-604, 2008.

Zito JM, Craig TJ and Wanderling J: Pharmacoepidemiology of 330 child/adolescent psychiatric patients Journal of Pharmacoepidemiology 3:47-62, 1994.

Zito JM, Safer DJ, de Jong-van den Berg LT, Janhsen K, Fegert JM, Gardner JF, Glaeske G and Valluri SC: A three-country comparison of psychotropic medication prevalence in youth. Child Adolesc Psychiatry Ment Health 2:26, 2008. 
Table 1. Psychotropic drugs approved in Switzerland in children and adolescents for psychiatric indications a

\begin{tabular}{|c|c|}
\hline Drugs & Indications \\
\hline \multicolumn{2}{|l|}{ Antipsychotics } \\
\hline $\begin{array}{l}\text { Typical antipsychotics } \\
\text { haloperidol (oral) } \\
\text { promazine }\end{array}$ & $\begin{array}{l}\text { schizophrenia ( } \geq 3 \text { years), mania ( } \geq 3 \text { years), agitation ( } \geq 3 \text { years) } \\
\text { acute crisis of chronic psychotic disorder ( } \geq 12 \text { years) }\end{array}$ \\
\hline $\begin{array}{l}\text { Atypical antipsychotics } \\
\text { aripiprazole (oral) } \\
\text { quetiapine (IR }{ }^{\mathrm{d}} \text { ) } \\
\text { risperidone (oral) }\end{array}$ & $\begin{array}{l}\text { schizophrenia ( } \geq 13 \text { years) }{ }^{b} \text {, manic or mixed episodes in bipolar I disorder ( } \geq 13 \text { years) }{ }^{c} \\
\text { schizophrenia ( } \geq 13 \text { years) }{ }^{e} \text {, manic episodes in bipolar disorder }\left(\geq 10 \text { years) }{ }^{e}\right. \\
\text { behavior disorders in mental retardation ( } \geq 5 \text { years), hyperactivity and irritability in autistic } \\
\text { disorders ( } \geq 5 \text { years), manic episodes in bipolar disorder ( } \geq 15 \text { years) }\end{array}$ \\
\hline \multicolumn{2}{|l|}{ Antidepressants } \\
\hline $\begin{array}{l}\text { Tricyclic antidepressants } \\
\text { clomipramine }\end{array}$ & obsessive compulsive disorder ( $\geq 10$ years) \\
\hline $\begin{array}{l}\text { Selective serotonin reuptake i } \\
\text { fluvoxamine } \\
\text { sertraline }\end{array}$ & $\begin{array}{l}\text { bitors } \\
\text { obsessive compulsive disorder ( } \geq 8 \text { years) } \\
\text { obsessive compulsive disorder ( } \geq 6 \text { years) }\end{array}$ \\
\hline \multicolumn{2}{|l|}{ Anxiolytics/hypnotics } \\
\hline $\begin{array}{l}\text { Benzodiazepines and analog } \\
\text { bromazepam } \\
\text { clobazam } \\
\text { clorazepate (oral) } \\
\text { diazepam (oral + injection) } \\
\text { lorazepam (oral) } \\
\text { oxazepam } \\
\text { prazepam } \\
\text { zolpidem }\end{array}$ & $\begin{array}{l}\text { anxiety ( } \geq \text { children) } \\
\text { anxiety ( } \geq 3 \text { years) } \\
\text { anxiety ( } \geq 9 \text { years) } \\
\text { anxiety ( } \geq \text { children) } \\
\text { anxiety ( } \geq 12 \text { years) } \\
\text { anxiety ( } \geq 12 \text { years) } \\
\text { anxiety ( } \geq 3 \text { years) } \\
\text { - } f\end{array}$ \\
\hline $\begin{array}{l}\text { Antihistaminics } \\
\text { diphenhydramine } \\
\text { doxylamine } \\
\text { hydroxyzine }\end{array}$ & $\begin{array}{l}\text { sleep disorders ( } \geq 2 \text { years) } \\
\text { sleep disorders ( } \geq 12 \text { years) } \\
-9\end{array}$ \\
\hline \multicolumn{2}{|c|}{ Attention deficit hyperactivity disorder (ADHD) } \\
\hline $\begin{array}{l}\text { atomoxetine } \\
\text { dexmethylphenidate } \\
\text { lisdexamphetamine } \\
\text { methylphenidate }\end{array}$ & $\begin{array}{l}\text { ADHD ( } \geq 6 \text { years) } \\
\text { ADHD ( } \geq 6 \text { years) } \\
\text { ADHD in case of inadequate response to methylphenidate ( } \geq 6 \text { years) } \\
\text { ADHD ( } \geq 6 \text { years) }\end{array}$ \\
\hline \multicolumn{2}{|l|}{ Others } \\
\hline $\begin{array}{l}\text { biperiden (IR d, injection) } \\
\text { lithium } \\
\text { nicotine }\end{array}$ & $\begin{array}{l}\text { extrapyramidal disorders ( } \geq 0 \text { year for injection; } \geq 3 \text { years for } I R) \\
\text { acute phase and long term prophylaxis of bipolar disorder ( } \geq 12 \text { years), co-medication } \\
\text { with antidepressants for resistant depression ( } \geq 12 \text { years) } \\
\text { - } h\end{array}$ \\
\hline
\end{tabular}

a according to www.compendium.ch (last update August 2017); b since 2009; c since 2013; d IR: oral form with immediate release; ${ }^{\text {e }}$ since $2010 ;{ }^{f}$ initially contraindicated in adolescents $<15$ years, suggesting a possible use in adolescents $\geq 15$ years, but the label has changed in 2009 stating that zolpidem should not be used in patients $<18$ years; 9 initially approved for anxiety in children and adolescent $\geq 1$ year, but this indication was withdrawn in 2016 ; $h$ approved in adults for smoking cessation, but could be used in adolescents $\geq 12$ years with strong dependence to nicotine. 


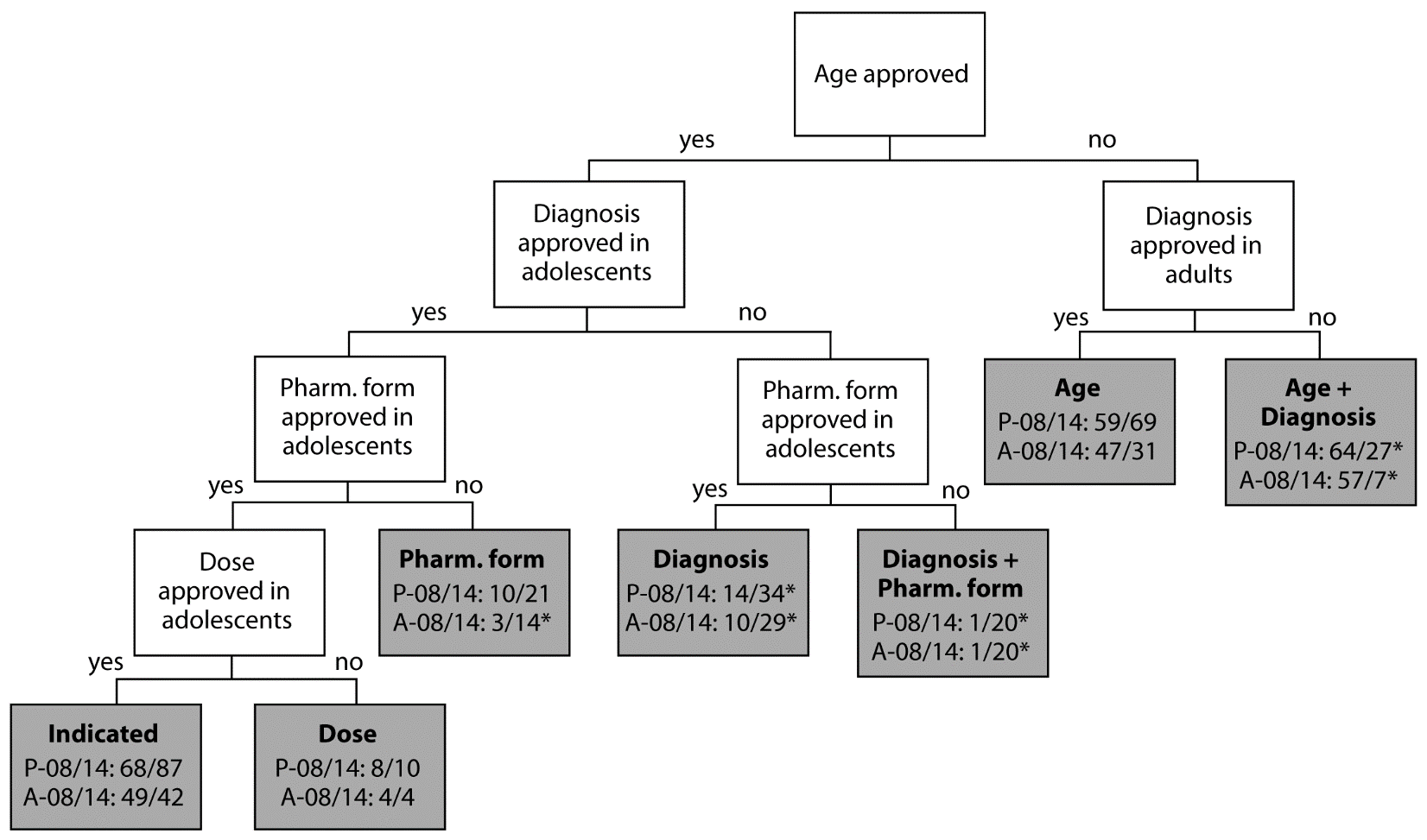


Table 2. ICD-10 psychiatric diagnoses of the patients

\begin{tabular}{|c|c|c|c|}
\hline \multirow[b]{2}{*}{ Diagnoses $^{a}$} & \multicolumn{2}{|c|}{ Number (\%) of patients ${ }^{b}$} & \multirow[b]{2}{*}{$P$-value } \\
\hline & $\begin{array}{c}\text { Year } 2008 \\
n=76\end{array}$ & $\begin{array}{c}\text { Year } 2014 \\
n=76\end{array}$ & \\
\hline $\begin{array}{l}\text { F10-19: Mental and behavioural disorders due to psychoactive } \\
\text { substance use }\end{array}$ & $8(10.5)$ & $5(6.6)$ & 0.56 \\
\hline F20-29: Schizophrenia, schizotypal and delusional disorders & $7(9.2)$ & $7(9.2)$ & 1.00 \\
\hline F30-39: Mood [affective] disorders & $25(32.9)$ & $29(38.2)$ & 0.61 \\
\hline F40-48: Neurotic, stress-related and somatoform disorders & $19(25.0)$ & $28(36.8)$ & 0.16 \\
\hline $\begin{array}{l}\text { F50-59: Behavioral syndromes associated with physiological } \\
\text { disturbances and physical factors }\end{array}$ & $11(14.5)$ & $4(5.3)$ & 0.10 \\
\hline F60-69: Disorders of adult personality and behavior & $3(3.9)$ & $5(6.6)$ & 0.72 \\
\hline F70-79: Mental retardation & $1(1.3)$ & $1(1.3)$ & 1.00 \\
\hline F80-89: Disorders of psychological development & $4(5.3)$ & $10(13.2)$ & 0.16 \\
\hline $\begin{array}{l}\text { F90-98: Behavioral and emotional disorders with onset usually } \\
\text { occurring in childhood and adolescence }\end{array}$ & $16(21.1)$ & $17(22.4)$ & 1.00 \\
\hline X60-X84: Intentional self-harm & $11(14.5)$ & $17(22.4)$ & 0.30 \\
\hline Z55-65 and Z80-99: Persons with potential health hazards & $15(19.7)$ & $20(26.3)$ & 0.44 \\
\hline $\begin{array}{l}\text { Q86: Congenital malformation syndromes due to known } \\
\text { exogenous causes, not elsewhere classified }\end{array}$ & $0(0.0)$ & $3(3.9)$ & 0.25 \\
\hline
\end{tabular}

${ }^{a}$ diagnoses at discharge ; ${ }^{b}$ one or more diagnoses per patient ; ${ }^{*}$ Fisher's exact test 


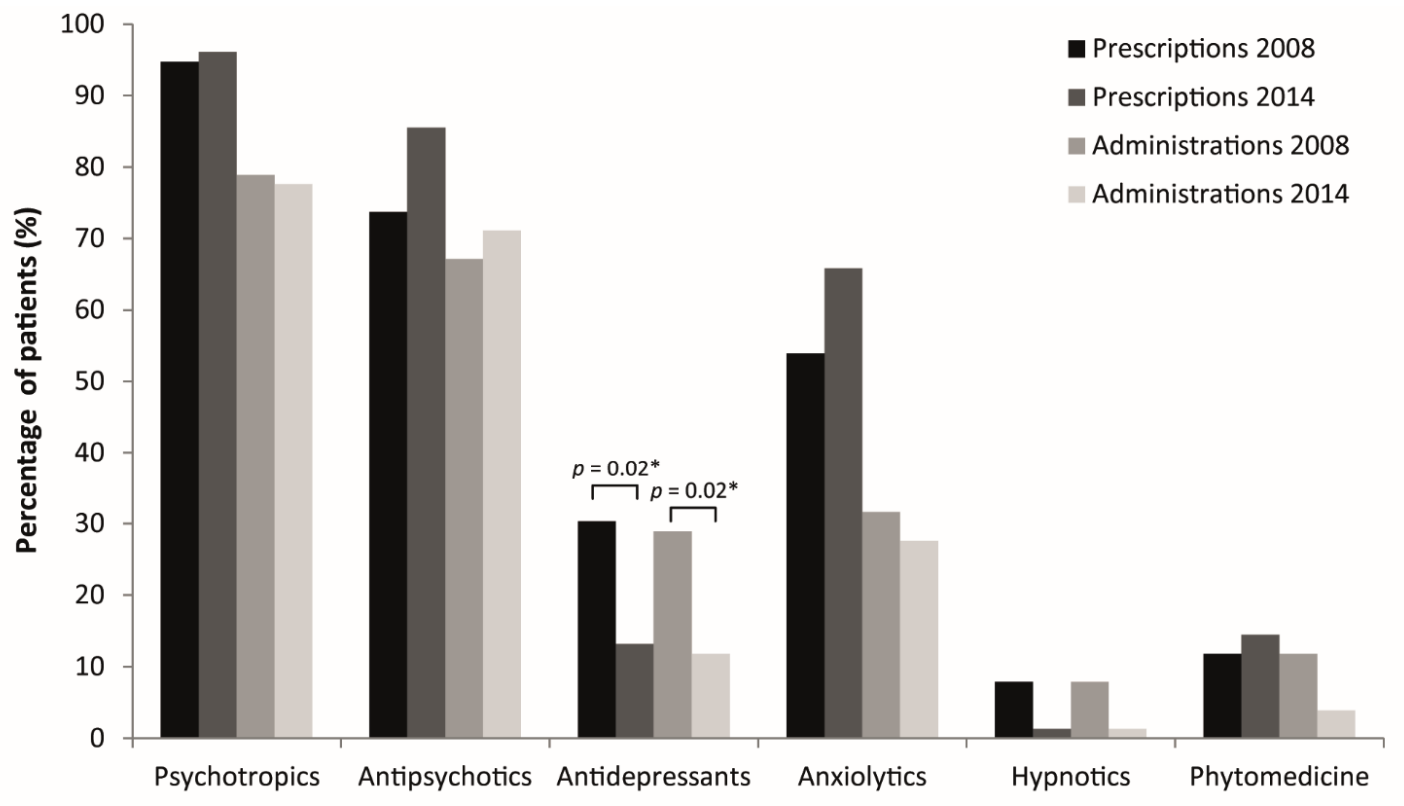

Therapeutic classes of drugs prescribed/administered at least once 
Table 3. Prescriptions of psychotropic drugs in hospitalized adolescents in 2008 ( $n=76$ patients) and 2014 ( $n=76$ patients)

\begin{tabular}{|c|c|c|c|c|c|c|c|c|}
\hline \multirow[t]{2}{*}{ Drugs } & \multicolumn{2}{|c|}{$\begin{array}{c}\text { Prescriptions, } \\
\mathrm{n} \text { (mean/patient) }\end{array}$} & \multicolumn{2}{|c|}{ Off-label prescriptions, $n(\%)^{a}$} & \multicolumn{2}{|c|}{ Dose [mg/day], median $\left(\right.$ range) ${ }^{\mathrm{b}}$} & \multicolumn{2}{|c|}{$\begin{array}{c}\text { Duration of prescription [day], } \\
\text { median (range) }\end{array}$} \\
\hline & 2008 & 2014 & 2008 & 2014 & 2008 & 2014 & 2008 & 2014 \\
\hline \multicolumn{9}{|l|}{ Antipsychotics } \\
\hline Levomepromazine (oral) & 31 & 44 & $31(100 \%)$ & $44(100 \%)$ & $50(15-108)$ & $60(15-164)$ & $16(3-111)$ & $15(4-56)$ \\
\hline Levomepromazine (inj) & $15^{*}$ & 35 * & $15(100 \%)$ & $35(100 \%)$ & $50(13-78)$ & $50(20-109)$ & $8(3-28)$ & $15(3-84)$ \\
\hline 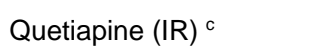 & 15 & 22 & $15(100 \%)$ * & $13(59.1 \%)$ * & $274(25-485) \#$ & $82.5(25-400) \#$ & $17(1-108)$ & $13(1-86)$ \\
\hline Quetiapine (XR) d & 2 * & 34 * & $2(100 \%)$ & $34(100 \%)$ & $131(50-213)$ & $254(50-800)$ & $32(1-63)$ & $14(2-58)$ \\
\hline Risperidone & 15 & 13 & $8(53.3 \%)$ & $10(76.9 \%)$ & $2(0.5-4)$ & $1(0.5-3.4)$ & $8(3-28)$ & $14(2-138)$ \\
\hline Chlorprothixene & $12^{*}$ & $1^{*}$ & $12(100 \%)$ & $1(100 \%)$ & $30(15-75)$ & $30(30-30)$ & $11(2-38)$ & $4(4-4)$ \\
\hline Haloperidol (oral) & 1 & 5 & $1(100 \%)$ & $4(80 \%)$ & $30(30-30)$ & $2.7(2-21)$ & $15(15-15)$ & $7(2-74)$ \\
\hline Haloperidol (inj) & 6 & 6 & $6(100 \%)$ & $6(100 \%)$ & $5(5-10)$ & $7.5(5-15)$ & $14(2-22)$ & $8.5(4-84)$ \\
\hline Amisulpride & 4 & 3 & $4(100 \%)$ & $3(100 \%)$ & $600(600-644)$ & $200(190-719)$ & $20(3-64)$ & $14(4-36)$ \\
\hline Aripiprazole & 1 & 2 & $1(100 \%)$ & $1(50 \%)$ & $10(10-10)$ & $6.8(5.7-7.8)$ & $12(12-12)$ & $12(7-16)$ \\
\hline Clozapine & 1 & 0 & $1(100 \%)$ & - & $218(218-218)$ & - & $10(10-10)$ & - \\
\hline Subtotal & $119(1.6)^{\#}$ & $170(2.2) \#$ & $112(94.1 \%)$ & $156(91.8 \%)$ & & & & \\
\hline \multicolumn{9}{|l|}{ Antidepressants } \\
\hline Citalopram & 12 * & 1 * & $12(100 \%)$ & $1(100 \%)$ & $20(10-60)$ & $20(20-20)$ & $15(4-100)$ & $30(30-30)$ \\
\hline Escitalopram & 4 & 0 & $4(100 \%)$ & - & $10(10-15)$ & - & $49(3-92)$ & - \\
\hline Mirtazapine & 4 & 0 & $4(100 \%)$ & - & $27(20-30)$ & - & $35(9-107)$ & - \\
\hline Sertraline & 1 * & 9 * & $1(100 \%)$ & $9(100 \%)$ & $50(50-50)$ & $50(46-100)$ & $11(11-11)$ & $16(2-89)$ \\
\hline Fluoxetine & 1 & 0 & $1(100 \%)$ & - & $40(40-40)$ & - & $7(7-7)$ & - \\
\hline Clomipramine & 1 & 0 & $1(100 \%)$ & - & $25(25-25)$ & - & $15(15-15)$ & - \\
\hline Duloxetine & 0 & 1 & - & $1(100 \%)$ & - & $30(30-30)$ & - & $96(96-96)$ \\
\hline Subtotal & $23(0.30)^{\#}$ & $11(0.14) \#$ & $23(100.0 \%)$ & $11(100.0 \%)$ & & & & \\
\hline \multicolumn{9}{|l|}{ Hypnotics } \\
\hline Zolpidem & $6^{*}$ & 0 * & $3(50 \%)$ & - & $9(5-12.5)$ & - & $9.5(2-33)$ & - \\
\hline Zopiclone & 3 & 1 & $3(100 \%)$ & $1(100 \%)$ & $7.5(4-7.5)$ & $7.5(7.5-7.5)$ & $12(2-26)$ & $11(11-11)$ \\
\hline Subtotal & $9(0.12)$ & $1(0.01)$ & $6(66.7 \%)$ & $1(100.0 \%)$ & & & & \\
\hline
\end{tabular}


Table 3. (continued)

\begin{tabular}{|c|c|c|c|c|c|c|c|c|}
\hline \multirow[t]{2}{*}{ Drugs } & \multicolumn{2}{|c|}{$\begin{array}{l}\text { Prescriptions, } \\
\text { n (mean/patient) }\end{array}$} & \multicolumn{2}{|c|}{ Off-label prescriptions, $\mathbf{n}(\%)^{a}$} & \multicolumn{2}{|c|}{ Dose [mg/day], median (range) ${ }^{b}$} & \multicolumn{2}{|c|}{$\begin{array}{c}\text { Duration of prescription [day], } \\
\text { median (range) }\end{array}$} \\
\hline & 2008 & 2014 & 2008 & 2014 & 2008 & 2014 & 2008 & 2014 \\
\hline \multicolumn{9}{|l|}{ Anxiolytics } \\
\hline Lorazepam (oral) & 39 & 48 & $3(7.7 \%)$ & $5(10.4 \%)$ & $3(1-17)$ & $3(1-11)$ & $12(1-64)$ & $16(1-96)$ \\
\hline Lorazepam (inj) & 4 & 1 & $4(100 \%)$ & $1(100 \%)$ & $5.5(2-12)$ & $8(8-8)$ & $10(7-17)$ & $3(3-3)$ \\
\hline Oxazepam & 2 & 0 & $0(0 \%)$ & - & $38(31-45)$ & - & $18(3-32)$ & - \\
\hline Alprazolam & 1 & 0 & $1(100 \%)$ & - & $1.5(1.5-1.5)$ & - & $4(4-4)$ & - \\
\hline Bromazepam & 1 & 0 & $0(0 \%)$ & - & $3(3-3)$ & - & $3(3-3)$ & - \\
\hline Clorazepate & 1 & 1 & $0(0 \%)$ & $0(0 \%)$ & $5(5-5)$ & $10(10-10)$ & $7(7-7)$ & $14(14-14)$ \\
\hline Diazepam & 0 & 1 & - & $0(0 \%)$ & - & $10(10-10)$ & - & $5(5-5)$ \\
\hline Hydroxyzine & 0 & 2 & - & $0(0 \%)$ & - & $74(48-100)$ & - & $13(12-14)$ \\
\hline Subtotal & $48(0.63)$ & $53(0.70)$ & $8(16.7 \%)$ & $6(11.3 \%)$ & & & & \\
\hline \multicolumn{9}{|l|}{ Phytotherapy } \\
\hline Phytotherapy "Sleep" e & 9 & 6 & $0(0 \%)$ & $0(0 \%)$ & $1(1-1)^{h}$ & $1(1-1)^{h}$ & $27(6-84)$ & $18(5-63)$ \\
\hline Phytotherapy "Sleep Strong" ${ }^{\dagger}$ & 1 & 5 & $0(0 \%)$ & $0(0 \%)$ & $1(1-1)^{h}$ & $1(1-1)^{h}$ & $67(67-67)$ & $19(3-22)$ \\
\hline Phytotherapy "Relaxing" g & 1 & 2 & $0(0 \%)$ & $0(0 \%)$ & $1(1-1)^{h}$ & $1.6(1.2-2)^{\mathrm{h}}$ & $25(25-25)$ & $37(10-63)$ \\
\hline Subtotal & $11(0.14)$ & $13(0.17)$ & $0(0.0 \%)$ & $0(0.0 \%)$ & & & & \\
\hline \multicolumn{9}{|l|}{ Others } \\
\hline Nicotine & 6 * & 0 * & $0(0 \%)$ & - & $8(6-16)$ & - & $14(5-19)$ & - \\
\hline Biperiden $(\mathrm{IR})^{\mathrm{c}}$ & 3 & 8 & $0(0 \%)$ & $0(0 \%)$ & $3.5(2-5) \#$ & $2(1-2) \#$ & $22(2-22)$ & $15(3-84)$ \\
\hline Biperiden $(X R)^{d}$ & 1 & 4 & $1(100 \%)$ & $4(100 \%)$ & $4(4-4)$ & $3(2-4)$ & $14(14-14)$ & $19(11-82)$ \\
\hline Biperiden (inj) & 2 & 5 & $0(0 \%)$ & $1(20 \%)$ & $4(3-5)$ & $5(2.5-7.5)$ & $8.5(3-14)$ & $4(3-84)$ \\
\hline Valproate & 1 & 0 & $1(100 \%)$ & - & $600(600-600)$ & - & $20(20-20)$ & - \\
\hline Methylphenidate & 1 & 0 & $1(100 \%)$ & - & $36(36-36)$ & - & $4(4-4)$ & - \\
\hline Atomoxetine & 0 & 1 & - & $0(0 \%)$ & - & $25(25-25)$ & - & $15(15-15)$ \\
\hline Lamotrigine & 0 & 1 & - & $1(100 \%)$ & - & $12.5(12.5-12.5)$ & - & $6(6-6)$ \\
\hline Melatonin & 0 & 1 & - & $1(100 \%)$ & - & $3(3-3)$ & - & $8(8-8)$ \\
\hline Subtotal & $14(0.18)$ & $20(0.26)$ & $3(21.4 \%)$ & $7(35.0 \%)$ & & & & \\
\hline TOTAL & $224(2.9)^{\#}$ & $268(3.5){ }^{\#}$ & $152(67.9 \%)$ & $181(67.5 \%)$ & & & & \\
\hline
\end{tabular}

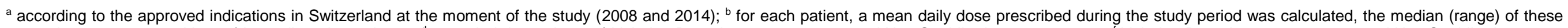

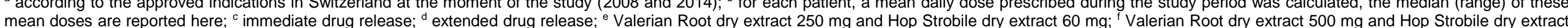

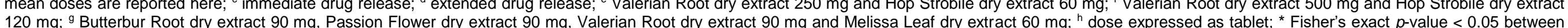
$120 \mathrm{mg}$; ${ }^{9}$ Butterbur Root dry extract $90 \mathrm{mg}$, Passion Flower dry extract 908 and 2014; " Mann-Whitney $p$-value $<0.05$ between 2008 and 2014. 

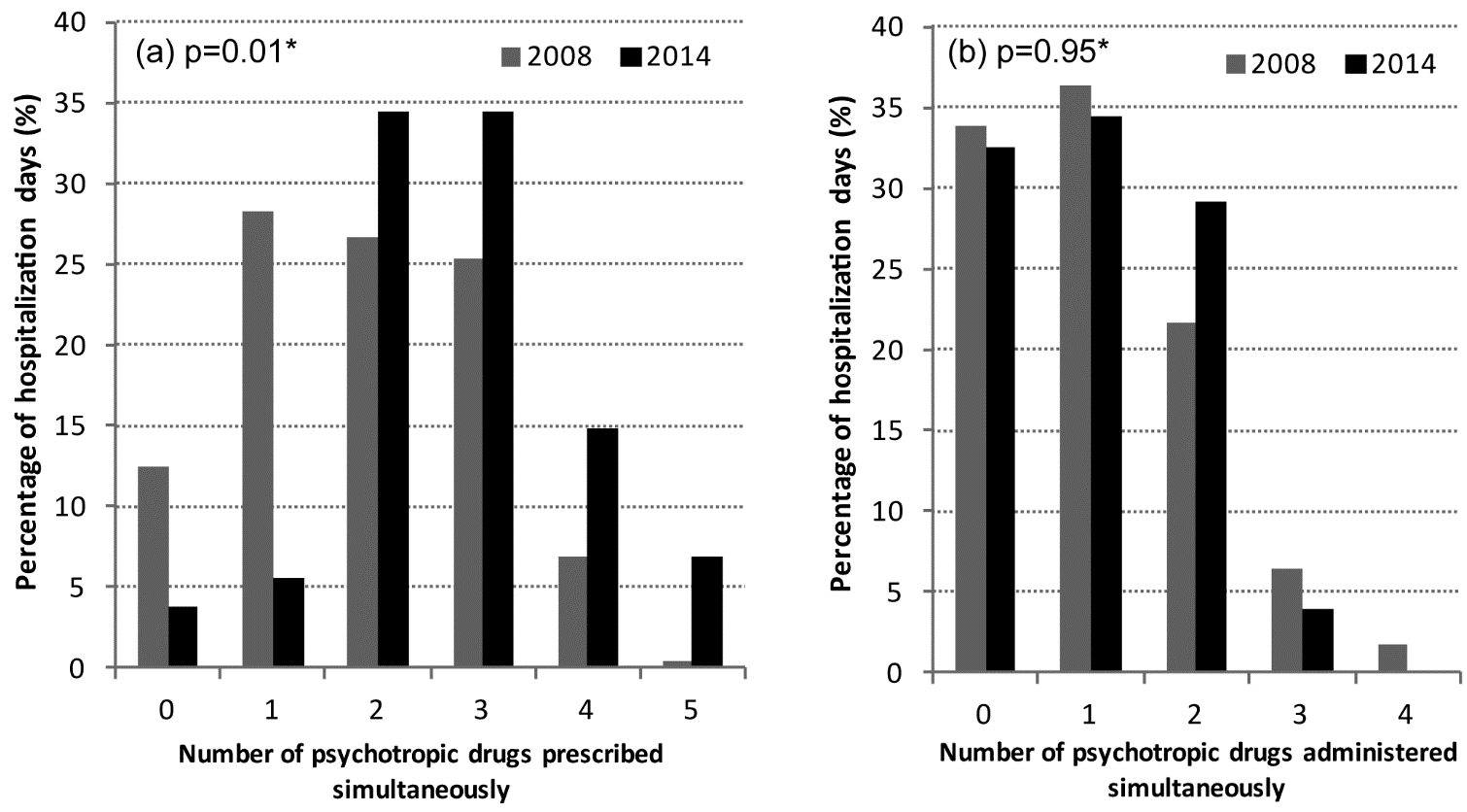


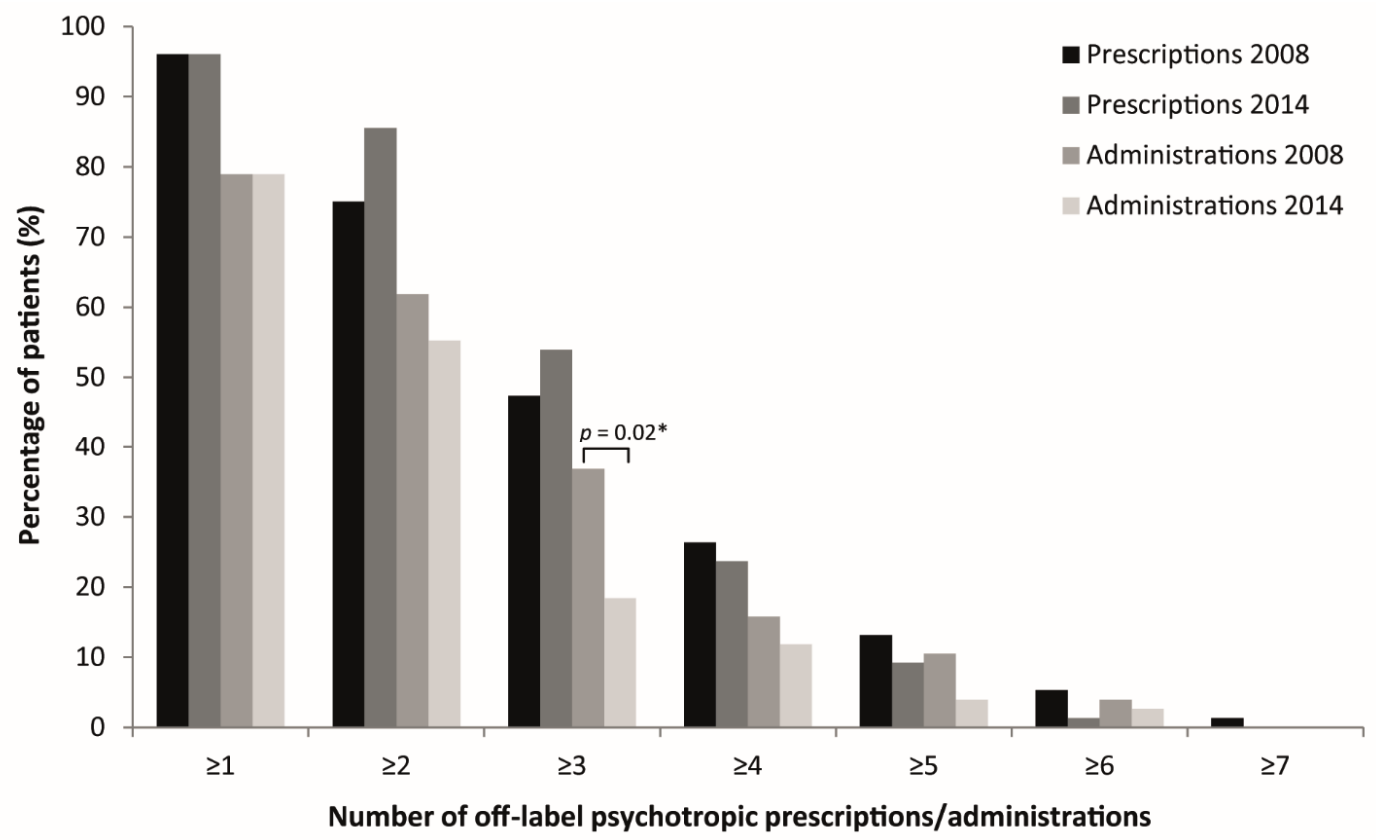




\section{Figure legends}

Fig. 1 Decision-tree classifying the reasons of off-label prescriptions and administrations. Pharm. form: Pharmaceutical form; P-08/14: number of prescriptions in 2008 and 2014, respectively; A-08/14: number of administrations in 2008 and 2014, respectively; *Fisher's exact $p$-value $<0.05$ between 2008 and 2014 .

Fig. 2 Percentage of patients with at least one prescription or administration of the different therapeutic classes of drugs. *Fisher's exact $p$-value between 2008 and 2014.

Fig. 3 Number of different psychotropic drugs prescribed (a) and administered (b) simultaneously per day in the same patient in 2008 and 2014. In 2014, 6 different psychotropic drugs were prescribed $0.1 \%$ of the days (data not shown in the figure). ${ }^{*}$ Poisson regression $p$-value between 2008 and 2014.

Fig. 4 Percentage of patients with off-label psychotropic prescriptions or administrations. *Fisher's exact $p$-value between 2008 and 2014. 